\title{
Real-time detection method for heavy metal pollution in soil of mining area
}

\author{
Yang Y. ${ }^{1}$, Zhao Y. ${ }^{1 *}$, Wang M. ${ }^{1}$, Meng H. ${ }^{1}$, and Ye Z. ${ }^{2}$ \\ ${ }^{1}$ Institute of Resources \& Environment, Henan Polytechnic University, Jiaozuo 454000, China \\ 2Environmental Monitoring Station, Jiaozuo City Ecological Environment Bureau, Jiaozuo 454003, China \\ Received: 02/07/2020, Accepted: 06/08/2020, Available online: 22/10/2020 \\ *to whom all correspondence should be addressed: e-mail: zhaoqi202@163.com \\ https://doi.org/10.30955/gnj.003386
}

\section{Graphical abstract}

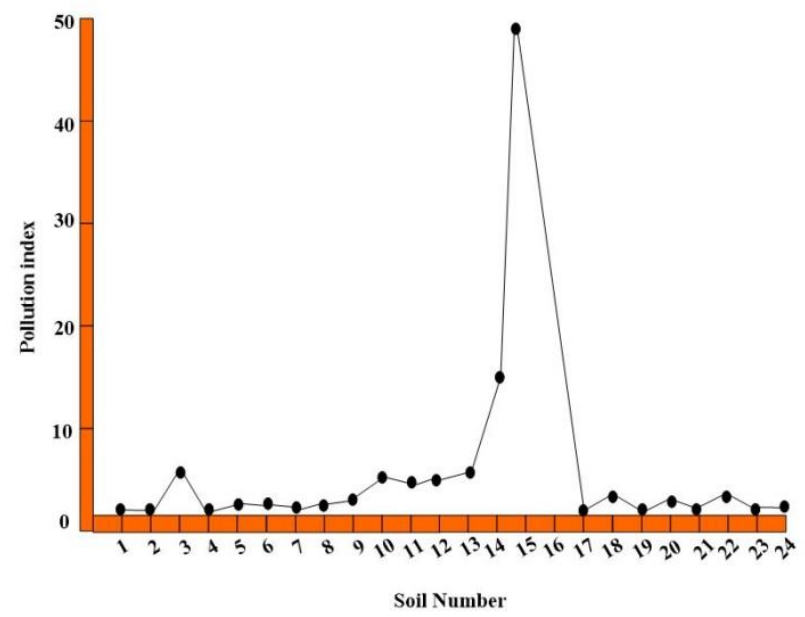

Abstract

Solid wastes and acid wastewater lead to the enrichment of heavy metals in the soil of mining area. Heavy metal pollution causes the decline of soil quality, ecosystem degradation, crop yield reduction, and even threatens human health. For this reason, the real-time detection method for heavy metal pollution in mining area is studied. Taking a mining area as an example, the data of heavy metal content in mining area soil are collected by PLSR model. Based on the collected data, the real-time detection model of heavy metal pollution in mining area soil based on improved analytic hierarchy process and weighted average method is adopted to real-time detect the heavy metal pollution index in the soil of mining area. The results show that the pollution index of $\mathrm{Cu}, \mathrm{Zn}$ and $\mathrm{Pb}$ in the soil of this mining area belongs to heavy pollution, and the pollution of $\mathrm{Cd}$ is relatively small. Among them, the pollution index of $\mathrm{Pb}$ is the largest among the four heavy metals, and the pollution is quite serious. The pollution sources of $\mathrm{Pb}, \mathrm{Zn}$ and $\mathrm{Cu}$ in this mining area are the same, and the pollution sources of $\mathrm{Cd}$ are different from those of other three heavy metals.
Keywords: Mining area, soil, heavy metal, pollution, realtime detection, analytic hierarchy process.

\section{Introduction}

Mineral resources are one of the basic sources of human production and life, but the development of mineral resources plays an important role in promoting the development of national economy, at the same time, it also brings serious environmental problems (Stihi et al., 2017; Rahman et al., 2020). In mining, especially in lead-zinc deposits and sulphur-containing polymetallic deposits, a large amount of heavy metals (Karbassi and Marefat, 2017) are enriched in the soil of mining area due to the direct discharge of mining wastewater and beneficiation wastewater, the stacking and leaching of solid wastes such as waste rocks and tailings. Heavy metals pose a great threat to the environment and human body. Most of the previous mining development work in China only focused on economic interests, and the research on heavy metals in mining soils was also lagging behind (Chen et al., 2017b; Zephania et al., 2019). The activity, bioavailability and toxicity of heavy metals in soils are closely related to the forms of heavy metals. It is not accurate to assess soil pollution in mining areas only by the total amount method of heavy metals (Stihi et al., 2017). Therefore, it is gradually on the agenda to study the sources, migration and transformation of heavy metals in mining soils, try to use a variety of soil heavy metal pollution assessment methods, accurately assess the grade and degree of soil pollution in mining areas, and carry out ecological reconstruction of mining areas (Yang et al., 2017; Paneru et al., 2020).

The results show that acidic mine wastewater and solid waste pollution are the main sources of heavy metals in soil (Nethaji et al., 2017). In the process of exploitation and utilization of primary sulfide deposits, waste sulfide minerals undergo long-term natural oxidation and rainwater leaching, resulting in a large number of heavy metals entering the soil of the mining area, and forming a certain range of supergene geochemical anomalies (Liu, 2017). The oxidation rate of sulfide minerals is related not only to reaction time, temperature, sulfide mineral content and types, but also to the external environment such as 
oxygen, water, biological activities, especially Ferrobacterium oxide. The production of acid wastewater is the result of the oxidation, weathering, decomposition of these primary sulfide minerals and the comprehensive reaction of water, acid, gas and minerals (Hamad et al., 2019). In addition, the contents of thallium, arsenic, lead and chromium in ores and surrounding rocks are very high. Dust pollution is also a source of heavy metals in soil during mining, transportation and dumping (Huang, 2017; Laili and Amid, 2019).

Some metals, especially toxic elements, can't be biodegraded once they enter the soil, mainly through a series of physical and chemical processes such as ion exchange, oxidation-reduction, adsorption/desorption, precipitation-dissolution, and finally exist in the soil in some form (Ramdani et al., 2018). In fact, toxicological effects caused by heavy metals have obvious lagging effect. The potential hazards and threats are much more serious than the apparent effects. Once pollution is formed, remediation will be very difficult and ineffective in the short term. The disasters caused by heavy metals are also sudden, that is, chemical time bombs. It is particularly necessary to monitor and evaluate heavy metals in soils of mining areas in time (Li and Shi, 2017). In this paper, a realtime detection method of heavy metal pollution in mining soil is proposed, which has important theoretical value for ecological detection of mining environment (Pang et al., 2017).

Table 1. Number scale and its description

\begin{tabular}{cc}
\hline Scale & Definition (comparative factors I and $\mathbf{j}$ ) \\
\hline 1 & Factor I is as important as factor $\mathrm{j}$ \\
\hline 3 & Factor I is slightly more important than factor $\mathrm{H}$ \\
\hline 5 & Factor I is more important than factor $\mathrm{H}$ \\
\hline 7 & Factor I is more important than factor $\mathrm{H}$ \\
\hline 9 & Factor I is absolutely more important than factor $\mathrm{H}$ \\
\hline $2,4,6,8$ & The Intermediate Value of Two Neighboring Judgements
\end{tabular}

Table 2. Average random consistency index

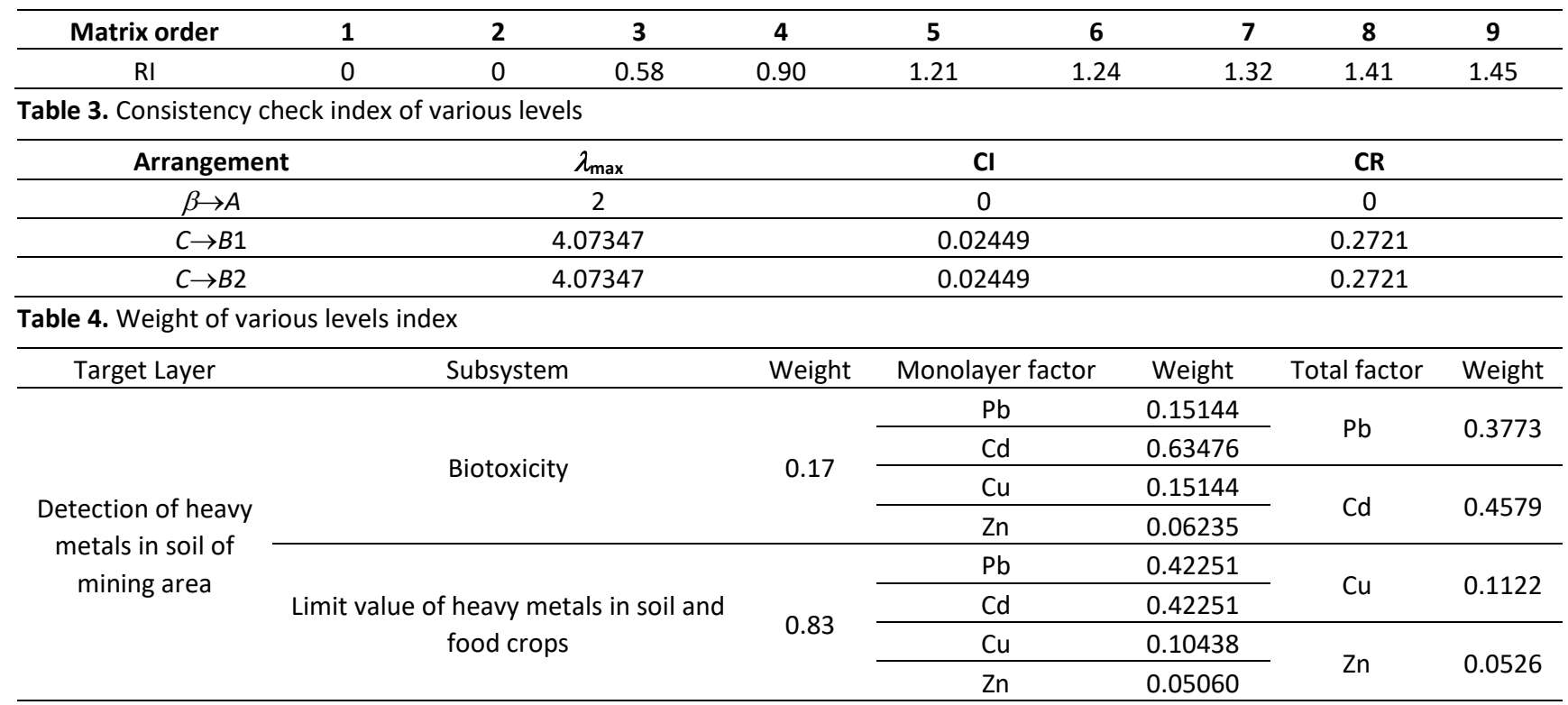

\section{Materials and methods}

\subsection{Data acquisition of heavy metals content in mine soil based on PLSR model}

The correlation wavelengths of heavy metal elements in mining soils are recorded as $\left[X=X_{1}, X_{2}, X_{3}, \ldots, X M\right]$ and $M=$ 150. The PCA method is used to reduce the dimension of descriptors of heavy metal elements in mining soils (Chen et al., 2017a; Ali et al., 2019). Firstly, standardization is carried out:

$$
X=(-\bar{X}) / \sqrt{D}
$$

In the formula, $X$ is a $M \times N$ matrix; $X$ is the mean of the bands related to heavy metals in the soil of the mining area; $D$ is the variance matrix of heavy metals in the soil of the mining area. The principal component of the set of bands related to heavy metals in mining soils can be obtained by the following formula:

$$
V^{T}\left(X X^{T}\right) V=\wedge
$$

In the formula, $\wedge$ is a diagonal matrix composed of eigenvalues $\beta_{i}(i=1,2,3, \ldots, M)$ and $\beta_{1} \geq \beta_{2} \geq \ldots \geq \beta_{M}$ of heavy metal elements in mining soil, and $\mathrm{V}$ is an orthogonal matrix composed of eigenvector $(i=1,2,3, \ldots, M)$ corresponding to eigenvalues of heavy metal elements in mining soil (Cheng et al., 2019). The eigenvectors corresponding to the eigenvalues of heavy metals in the soils of the first three large mining areas are selected as independent variables, such as W330, W790 and W1440. Then the combinations of these variables are analyzed by 
multiple linear regression (Leung et al., 2017; Prabal et al., 2020). The regression equation is derived.

$$
\begin{aligned}
O= & 76.454 W 330-2.976 W 790 \\
& +23.255 W 1440-56.232
\end{aligned}
$$

Where, $O$ is the content of heavy metals in the soil of mining area. The model of extracting heavy metals from soil in mining area is established as follows:

$$
O=73.542 W 345-3.355 W 760+20.794 W 1590-0.862
$$

2.2. Real-time detection model of heavy metal pollution in mining soil based on improved analytic hierarchy process and weighted average method

\subsubsection{Detection of single factor pollution index}

The pollution index detection formula of single factor $O_{i}$ is as follows:

$$
O_{i} P_{i}=C_{i} / S_{i}
$$

In the formula, $P_{i}$ is the pollution coefficient of heavy metals in the soil of mining area, $C_{i}$ is the actual value of the pollution coefficient of heavy metals in the soil of mining area, and $S_{i}$ is the detection standard of heavy metals in the soil of mining area. Among them, $O_{i}$ can be refined into various kinds of heavy metals in the soil of the metallogenic area according to the detected components.

\subsubsection{Detection of multifactor pollution index}

(1) Establishment of analytical hierarchy process

The first layer of the hierarchical analysis structure for the detection of heavy metal pollution in mining area soil is the target layer, that is, to detect the heavy metal pollution in a mining area soil, which is defined as layer A; The second layer is the standard layer, that is, to select two standards of the limit values of heavy metals such as $\mathrm{Pb}, \mathrm{Cd}, \mathrm{Cu}$ and $\mathrm{Zn}$ in the soil of the mining area $\left(0.2,0.2,10\right.$ and $50 \mathrm{mg} \cdot \mathrm{kg}^{-1}$, respectively) and the toxicity response coefficient of heavy metals $(5,30,5$ respectively) 1$)$, to be defined as layer $B$, two of which are defined as $B_{1}$ and $B_{2}$ respectively; the third layer is a specific detection factor, namely four heavy metal elements of lead, cadmium, copper and zinc, defined as layer C; The analytic hierarchy is a three-layer structure (Ramdani et al., 2018; Amjad et al., 2019).

\section{(2) Construction of judgment matrix}

At each level, the indicators of this layer are compared one by one. According to the prescribed scaling method, the judgment matrix of heavy metal pollution in mining area soil is written. The scaling and its description are shown in Table 1.

According to the prescribed scaling method, the $A \rightarrow B$ layer judgment matrix (6), the $B_{1} \rightarrow C$ judgment matrix (7) and the $\beta_{2} \rightarrow C$ judgment matrix (8) for the real-time detection of heavy metal pollution in mining soils are established.

$$
\left[\begin{array}{cc}
1 & 1 / 5 \\
5 & 1
\end{array}\right]
$$

$\left[\begin{array}{cccc}1 & 1 / 5 & 1 & 3 \\ 5 & 1 & 5 & 7 \\ 1 & 1 / 5 & 1 & 3 \\ 1 / 3 & 1 / 7 & 1 / 3 & 1\end{array}\right]$

$$
\left[\begin{array}{cccc}
1 & 1 & 5 & 7 \\
1 & 1 & 5 & 7 \\
1 / 5 & 1 / 5 & 1 & 3 \\
1 / 7 & 1 / 7 & 1 / 3 & 1
\end{array}\right]
$$

(3) Computation of matrix eigenvector and maximum eigenvalue

The approximate calculation method for the characteristic vector of the $\mathrm{O}$ matrix of the heavy metal content in the soil of mining area is as follows: firstly, the judgment matrix is summed by rows, then the average values of each row are obtained, and a column vector of the heavy metal content in the soil of mining area is obtained (Khoo et al., 2019). Dividing each element of the vector by the sum of all elements of the column vector, the column vector thus obtained is the eigenvector $W$ of heavy metals in the soil of the mining area. (Leung et al., 2018). Based on the eigenvectors of heavy metals in mining soils, the algorithm of maximum eigenvalue $\lambda_{\max }$ of heavy metals in mining soils is as follows:

$$
O \lambda_{\max }=\sum_{i=1}^{n} \frac{(C \cdot W)_{i}}{n \cdot w_{i}}
$$

In the formula, $W$ is the eigenvector of heavy metals in mining area soil, $w_{i}$ is the $i$-th element in the eigenvector, $C$ is the judgment matrix of heavy metals pollution in mining area soil, and $n$ is the order of the judgment matrix of heavy metals pollution in mining area soil.

\section{(4) Consistency test}

According to the constructed judgment matrix of heavy metal pollution in mining area soil, the weights of all heavy metal pollution factors associated with the above level are calculated (Li et al., 2017). In order to measure the consistency of the judgment matrix of heavy metal pollution in mining area, the negative average $\mathrm{Cl}$ of other characteristic roots besides the maximum eigenvalue of the judgment matrix is introduced. The formula is as follows:

$$
\mathrm{Cl}=\frac{\lambda_{\max }-n}{n-1}
$$

In order to measure the consistency of different judgment matrices, the average random consistency index $\mathrm{RI}$ is introduced. The RI value is shown in Table 2.

When calculating the random consistency ratio $\mathrm{CR}=\mathrm{Cl} / \mathrm{RI}$, when $C R<0.10$, the matrix is considered to have satisfactory consistency. Otherwise, the judgment matrix of heavy metal contamination in mining area soil should be reconstructed until it has satisfactory consistency.

(5) Consistency test of hierarchical total sorting

The total ranking of the hierarchy uses the results of all the hierarchical ordering in the same hierarchy, and the 
weights of all the heavy metal elements in the upper hierarchy, to calculate the weight value of all heavy metal factors in this level for the detection of heavy metal pollution in the mining area (Rosen and Chen, 2018). The test is performed from the upper layer to the lower layer. For example, the consistency index of the factors in the layer $\mathrm{B}$ to the single order of the layer $\mathrm{A}$ is $\mathrm{Cl}_{i}$, and the average random consistency index is $\mathrm{Rl}_{i}$. The random consistency ratio of the total order of the layer $B$ is:

$$
\mathrm{CR}=\frac{\sum_{i=1}^{n} a_{i} \cdot \mathrm{Cl}_{i}}{\sum_{i=1}^{n} a_{i} \cdot \mathrm{Rl}_{i}}
$$

In the formula, $a_{i}$ is the weight value of heavy metal factor in layer $\mathrm{A}$. When $\mathrm{CR}<0.1$, the result of total ranking of layers is satisfactory. According to formula (11), the judgment matrix of soil heavy metal pollution in mining area is calculated. The consistency test results of each layer are shown in Table 3.

The consistency test meets the requirements. The normalized eigenvector corresponding to $\lambda_{\max }$ is the weight value of heavy metal elements in the soil of mining area. The weight of each index is shown in Table 4.

\subsubsection{Establishment of improved weighted average method}

The traditional formula of weighted average method is as follows:

$$
\begin{aligned}
& P_{i}=c_{i} / S_{i} \\
& P=\sum A_{i}\left(c_{i} / S_{i}\right)
\end{aligned}
$$

In the formula, $P_{i}$ is the pollution factor of heavy metal pollutants in mining area soil, $c_{i}$ is the average measured content of heavy metal pollutants in mining area soil $\left(\mathrm{mg} \cdot \mathrm{kg}^{-1}\right), S_{i}$ is the reference value of heavy metal pollutants in mining area soil $\left(\mathrm{mg} \cdot \mathrm{kg}^{-1}\right), A_{i}$ is the weight of a heavy metal element (where the weight is calculated by analytic hierarchy process), and $P$ is the comprehensive pollution index of heavy metal in mining area soil. There are usually two methods to determine the value of $S_{i}$ (MunozColmenares et al., 2017). One is to adopt the critical value of Class III soil standard in the national soil environmental quality standard, and the other is to take the arithmetic average value of various standard values. Because of the difference in the range of standard values of different types of soils, there are some deviations between the two methods (Shahsavari et al., 2019). In order to solve this problem, the weighted method is used to determine the $S_{i}$ value. Taking $\mathrm{Cd}$ as an example, the soil grade ranges of $\mathrm{Cd}$ are $[0,0.2],[0.2,0.3]$ and $[0.3,1]$ respectively, and the formula for calculating $S_{\mathrm{Cd}}$ is as follows:

$$
\frac{(0.2-0) \times 0.1+(0.3-0.2) \times 0.25+(1-0.3) \times 0.65}{(0.2-0)+(0.3-0.2)+(1-0.3)}=0.5
$$

Other heavy metal elements are calculated according to this method. The results are as follows: the value of $\mathrm{Pb}$ is
$250 \mathrm{mg} \cdot \mathrm{kg}^{-1}$, the value of $\mathrm{Cd}$ is $0.5 \mathrm{mg} \cdot \mathrm{kg}^{-1}$, the value of $\mathrm{Cu}$ is $200 \mathrm{mg} \cdot \mathrm{kg}^{-1}$, and the value of $\mathrm{Zn}$ is $250 \mathrm{mg} \cdot \mathrm{kg}^{-1}$.

\subsubsection{Comprehensive detection}

Based on the above method, a comprehensive detection model based on AHP and weighted average is obtained. The formula is as follows:

$$
\begin{aligned}
P= & {[\mathrm{Pb}] / 250 \cdot a_{\mathrm{Pb}}+[\mathrm{Cd}] / 0.5 \cdot a_{\mathrm{Cd}} } \\
& +[\mathrm{Cu}] / 200 \cdot a_{\mathrm{Cu}}+[\mathrm{Zn}] / 250 \cdot a_{\mathrm{Zn}}
\end{aligned}
$$

Where, $a$ is the corresponding weight of four heavy metal elements calculated based on improved AHP. Here, O calculated by formula (4) is refined into [Pb], [Cd], [Cu] and [Zn], which is the measured content value of heavy metals, and $\mathrm{P}$ is the comprehensive pollution index (Shalmashi and Khodadadi, 2019). On the basis of the new detection model, considering comprehensively the values of each grade of the national soil grade standard and the background values of the soil in the mining area, the new grading criteria are obtained after the calculation of the model: $P \leq 1$ means clean, $1<P \leq 2$ means light pollution, $2<P \leq 3$ means medium pollution, and $P>3$ means heavy pollution.

\subsection{Test settings}

Taking the major industrial developed cities in a certain area as the research area, this area is one of the most developed and fastest growing areas in China. However, the rapid development of industrialization and urbanization has also produced a large number of industrial wastes and domestic wastes, resulting in serious environmental problems (Chicalote-Castillo et al., 2017; Islam et al., 2020). Among them, the over-standard content of heavy metals in the soil of mining areas in this area is widespread, with the over-standard rates of $\mathrm{Cd}, \mathrm{Zn}$ and $\mathrm{Cu}$ reaching $40.1 \%, 19.8 \%$ and $8.1 \%$ respectively, which seriously threatens the safety of environmental management in mining areas.

In the sampling area, the heavy metal content of 24 sampling points is detected. Five points are taken from each sampling point in the range of $10 \mathrm{~m} \times 10 \mathrm{~m}$. After mixing, the samples are sampled by quartering method. After air-drying, the impurities are removed and the 0.15 $\mathrm{mm}$ pore size nylon sieve is reserved. The soil samples were digested by $\mathrm{HNO}_{3}-\mathrm{HF}-\mathrm{HClO}$ and the heavy metal contamination in the mining area is detected by the proposed method (Szentgyrgyi et al., 2017).

\section{Results}

\subsection{Statistical analysis of soil heavy metal content data in mining area}

Table 5 shows the statistical results of heavy metals in the soils of mining areas in this area.

According to Table 5, the average contents of $\mathrm{Pb}, \mathrm{Cd}, \mathrm{Cu}$ and $\mathrm{Zn}$ detected by the proposed method are 671, 24, 82 and $1179 \mathrm{mg} \cdot \mathrm{kg}^{-1}$, respectively, which are much higher than the background values of the corresponding heavy metal contents in the soils of this area, indicating that there 
is an obvious accumulation phenomenon. Among them, the average contents of $\mathrm{Cd}, \mathrm{Pb}$ and $\mathrm{Zn}$ are 301, 24 and 13 times of the background values of the corresponding soil heavy metals content in this area, which indicates that the pollution of $\mathrm{Cd}, \mathrm{Pb}$ and $\mathrm{Zn}$ in the soil of this mining area is significant and common (Liew et al., 2019). The contents

Table 5. Statistical results of heavy metals in soil of mining area in this area

\begin{tabular}{cccccccc}
\hline Heavy metal & $\begin{array}{c}\text { Number of } \\
\text { samples }\end{array}$ & Range & Minimum & $\begin{array}{c}\text { Maximum } \\
\text { value }\end{array}$ & Mean value & $\begin{array}{c}\text { Background } \\
\text { values in this area }\end{array}$ & The sum \\
\hline $\mathrm{Pb}$ & 141 & 4805 & 60 & 4864 & 671 & 27.3 & 94599 \\
\hline $\mathrm{Zn}$ & 141 & 8247 & 184 & 8431 & 1197 & 88.6 & 168734 \\
\hline $\mathrm{Cu}$ & 141 & 582 & 17 & 599 & 82 & 25.4 & 11549 \\
\hline $\mathrm{Cd}$ & 141 & 922 & 2.1 & 924 & 24 & 0.079 & 336 \\
\hline
\end{tabular}

Table 6. Test results of soil heavy metal pollution in mining area

\begin{tabular}{|c|c|c|c|c|c|c|}
\hline Number & $\mathrm{Cu}$ & $\mathrm{Zn}$ & $\mathrm{Pb}$ & Cd & $\begin{array}{c}\text { Composite } \\
\text { index }\end{array}$ & Pollution Degree \\
\hline 1 & 1.38 & 0.27 & 0.35 & 0.23 & 1.01 & Light pollution \\
\hline 2 & 0.85 & 0.23 & 0.41 & 0.14 & 0.67 & Clean grade \\
\hline 3 & 1.35 & 0.39 & 2.56 & 0.3 & 1.41 & Light pollution \\
\hline 4 & 0.83 & 1.18 & 0.56 & 0.41 & 0.99 & Heavy pollution \\
\hline 5 & 2.17 & 0.94 & 1.28 & 0.39 & 1.75 & Light pollution \\
\hline 6 & 1.01 & 0.33 & 1.56 & 0.13 & 1.23 & Light pollution \\
\hline 7 & 2.57 & 0.27 & 0.22 & 0.27 & 1.91 & Light pollution \\
\hline 8 & 3.11 & 0.81 & 0.8 & 0.28 & 1.54 & Light pollution \\
\hline 9 & 14 & 0.98 & 1.97 & 0.21 & 10.35 & Heavy pollution \\
\hline 10 & 18.96 & 1.87 & 4.97 & 0.18 & 14.17 & Heavy pollution \\
\hline 11 & 6.88 & 1.96 & 3.87 & 0.52 & 5.4 & Heavy pollution \\
\hline 12 & 1.01 & 1.45 & 4.98 & 0.21 & 3.77 & Heavy pollution \\
\hline 13 & 9.87 & 1.23 & 6.13 & 0.03 & 7.61 & Heavy pollution \\
\hline 14 & 3.58 & 6.66 & 6.98 & 0.34 & 5.83 & Heavy pollution \\
\hline 15 & 2.71 & 14.77 & 15.92 & 2.53 & 12.93 & Heavy pollution \\
\hline 16 & 3.74 & 10.03 & 49.34 & 1.23 & 36.7 & Heavy pollution \\
\hline 17 & 2.34 & 0.61 & 0.04 & 0.29 & 1.75 & Light pollution \\
\hline 18 & 3.7 & 0.26 & 2.85 & 0.28 & 2.9 & Medium pollution \\
\hline 19 & 21.97 & 0.32 & 0.25 & 0.28 & 16.05 & Heavy pollution \\
\hline 20 & 3.11 & 0.35 & 1.51 & 0.79 & 2.42 & Medium pollution \\
\hline 21 & 3.34 & 0.27 & 0.88 & 0.37 & 2.51 & Medium pollution \\
\hline 22 & 3.47 & 0.42 & 2.07 & 0.28 & 2.69 & Medium pollution \\
\hline 23 & 5.37 & 0.25 & 1.35 & 0.78 & 4.04 & Heavy pollution \\
\hline 24 & 1.61 & 0.73 & 1.47 & 0.92 & 1.41 & Light pollution \\
\hline Composite index & 15.93 & 10.53 & 35.05 & 1.82 & - & - \\
\hline Pollution Degree & Heavy pollution & $\begin{array}{c}\text { Heavy } \\
\text { pollution }\end{array}$ & Heavy pollution & $\begin{array}{l}\text { Light } \\
\text { pollution }\end{array}$ & - & - \\
\hline
\end{tabular}

Table 7. Pearson correlation coefficients of four heavy metals

\begin{tabular}{ccccc}
\hline & $\mathbf{P b}$ & $\mathrm{Zn}$ & $\mathrm{Cu}$ & $\mathrm{Cd}$ \\
\hline $\mathrm{Pb}$ & 1 & & & \\
\hline $\mathrm{Zn}$ & $0.646^{* *}$ & 1 & 1 & \\
\hline $\mathrm{Cu}$ & $0.737^{* *}$ & $0.696^{* *}$ & $0.448^{* *}$ & 1 \\
\hline $\mathrm{Cd}$ & $0.234^{* *}$ & $0.522^{* *}$ & \\
\hline
\end{tabular}

Note: ${ }^{* *}$ means significant correlation at level 0.01 (bilateral).

\subsection{Detection results of heavy metal pollution in soil of mining area}

The results of heavy metal contamination in soils from the 24 sampling sites are shown in Table 6.

According to Table 6, it can be seen that the pollution index of $\mathrm{Cu}, \mathrm{Zn}$ and $\mathrm{Pb}$ in the soil of the mining area belong to of $\mathrm{Pb}, \mathrm{Cd}, \mathrm{Cu}$ and $\mathrm{Zn}$ in the soils of the mining area range from 60 to $4864 \mathrm{mg} \cdot \mathrm{kg}^{-1}, 2.1$ to $924 \mathrm{mg} \cdot \mathrm{kg}^{-1}, 17$ to 599 $\mathrm{mg} \cdot \mathrm{kg}^{-1}$ and 184 to $8431 \mathrm{mg} \cdot \mathrm{kg}^{-1}$, respectively, which shows that the pollution situation in different areas varies greatly. 
Figures 1-4 are pollution index of four heavy metals in the soil of the mining area detected by the proposed method.

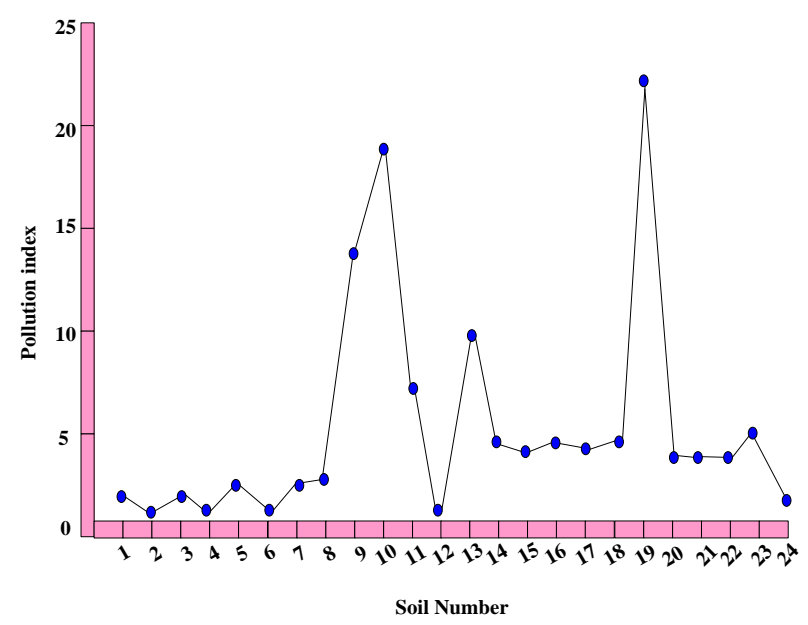

Figure 1. Pollution index of $\mathrm{Cu}$

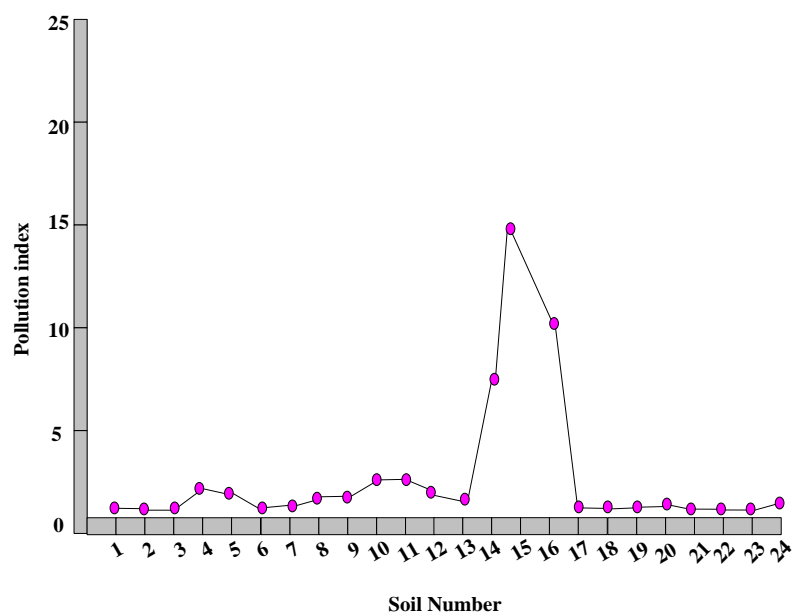

Figure 2. Zn pollution index

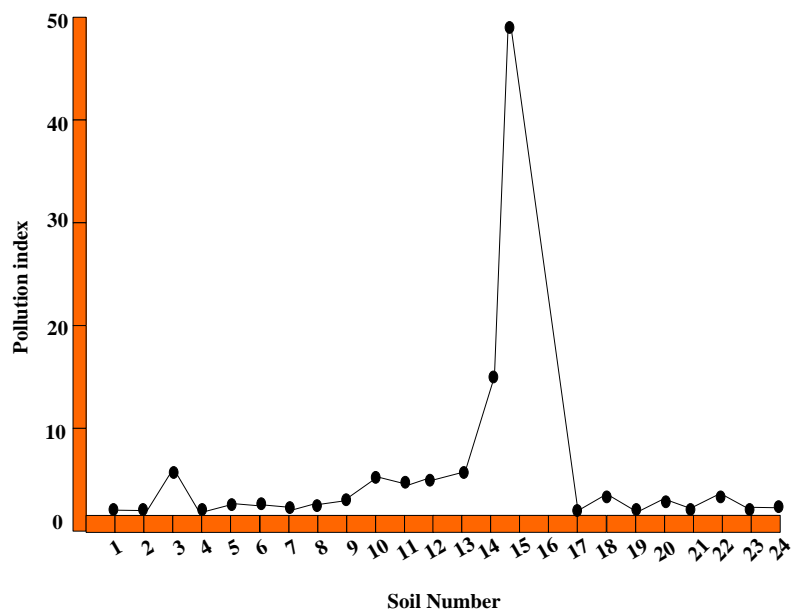

Figure 3. $\mathrm{Pb}$ pollution index

As can be seen from Figures 1-4, Cu pollution is the most common and serious (Figure 1). The comprehensive pollution index of $\mathrm{Zn}$ is 10.53 , the highest single pollution index is 15.17 , and the number of samples greater than 1 is 8 , accounting for $1 / 3$ of all samples (Figure 2 ). The $\mathrm{Pb}$ pollution index is the largest among the four heavy metals, and the pollution is quite serious, especially at sampling sites 15 and 16, the pollution index is as high as 15.92 and 49.34, respectively (Figure 3 ). The Cd pollution index of soil in this mining area is the smallest, which is 1.82, and the pollution degree is light pollution grade. Except for sampling sites 15 and 16 , most of the $\mathrm{Cd}$ pollution index are less than 1, which indicates that the $\mathrm{Cd}$ pollution index in this mining area are small (Figure 4).

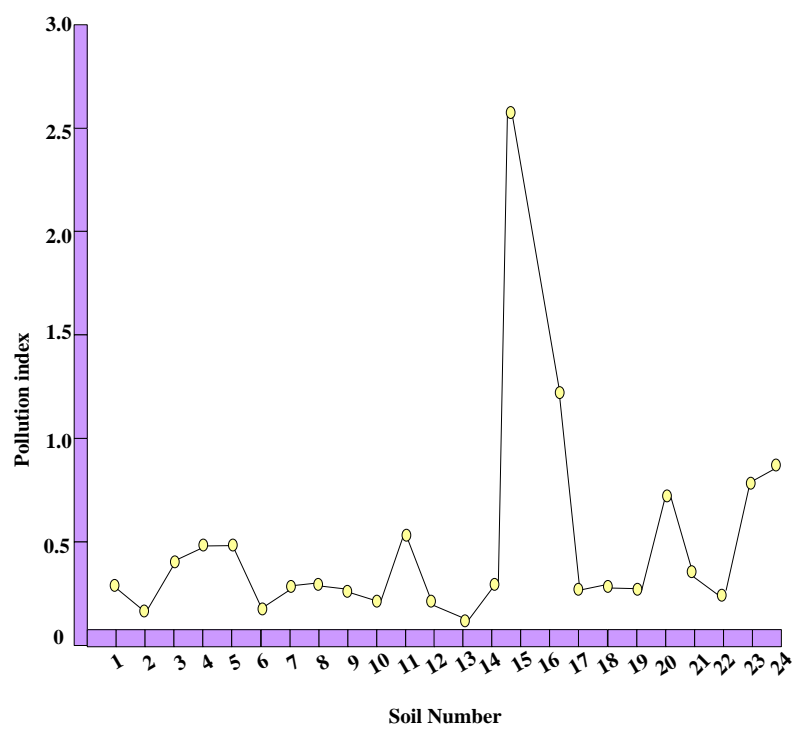

Figure 4. Cd pollution index

\subsection{Source analysis of heavy metals in soil of mining area}

Pearson correlation analysis of the four heavy metals detected in the above experiments is carried out to study the correlation among the four heavy metals and to analyze the main sources of heavy metal pollution in the soil of the mining area. The analysis results are shown in Table 7.

Table 7 shows that there is a significant correlation among the four heavy metals in the soil of the mining area $(p<0.01)$. It can be preliminarily judged that the sources of heavy metal pollution in the soil of the mining area have certain similarities. The investigation shows that the main activities in the local mining area are the beneficiation of lead-zinc ore and the smelting of non-ferrous metals. There are one beneficiation plant and five smelters in the sampling area. The main sources of heavy metals such as lead and zinc are the beneficiation wastewater and smelting gas. Because the sampling area is mainly around the concentrator and smelter, the sources of heavy metals in cultivated soil are closely related to the mining activities in the local mining area.

In order to further analyze the pollution sources of heavy metals in cultivated soil of this mining area, the principal component analysis of four heavy metals in cultivated soil of this mining area is carried out by factor analysis method (Ng et al., 2018). Through KMO and Bartlett sphericity test, the sampling data is suitable for factor analysis. The results are shown in Figure 5:

It can be seen from Figure 5 that $\mathrm{Cd}$ has higher load on component 2 , while $\mathrm{Pb}, \mathrm{Zn}$ and $\mathrm{Cu}$ have higher load on 
component 1. It can be concluded that $\mathrm{Cd}$ is different from other three sources of heavy metal pollution. Through sampling and investigation in and around the mining area, it is known that the main pollution sources of $\mathrm{Pb}, \mathrm{Zn}$ and $\mathrm{Cu}$ are the mining and smelting activities of lead-zinc sulfide ores in the mining area and the secondary pollution caused by slag after mining. In the smelting process of lead-zinc ore, $\mathrm{Cd}$ is one of the main associated products of lead-zinc ore. However, the areas with serious $\mathrm{Cd}$ pollution are all near the concentrator, which explains the source of pollution very well (Osazuwa et al., 2018). Therefore, the first principal component of $\mathrm{Cd}$ pollution source is mainly the mining activities of non-ferrous metal mines, and the second principal component is mainly the "three wastes" discharge from mining areas.

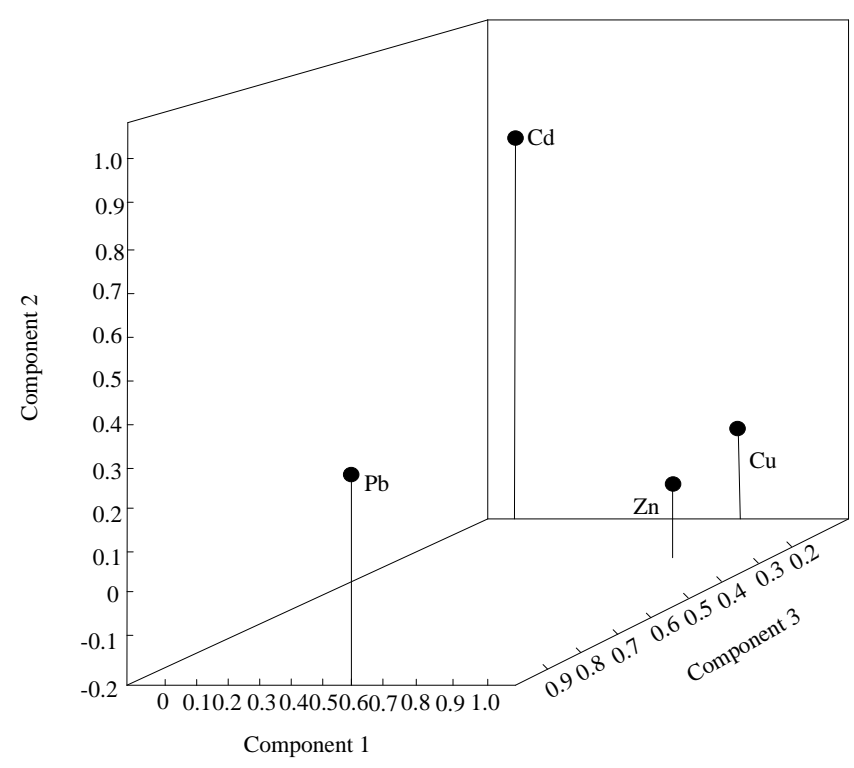

Figure 5. Factorial Load of Heavy Metals in Soil

\section{Discussions}

Real-time detection of heavy metal pollution in mining soils can provide the most basic data support for soil environmental remediation in mining areas. The following suggestions are put forward for the future restoration of soil environment in mining areas around the research topics in this paper:

\section{(1) Restoration of soil conditions}

In view of the characteristics of harsh microclimate, decrease of biological community and homogenization of ecosystem in mining area, bioremediation measures are adopted according to local conditions, including vegetation reconstruction, introduction and development of microorganisms and animals. The core of these measures is vegetation construction to form artificial plant communities. In general, fast-growing, adaptable, welldeveloped roots and strong stress-resistance plants are selected, and mixed allocation of grass, shrub and tree is adopted to combine short-term, medium-term and longterm development. Some beneficial soil animals (such as earthworms) and soil microorganisms are properly introduced and developed to restore the original climate, biology and ecosystem conditions.

\section{(2) Rehabilitation of soil physical and chemical properties}

For acidic mining areas where soil $\mathrm{pH}$ is not too low, bicarbonate or lime can be used to regulate soil acidity; for those with too low or high $\mathrm{pH}$, a small amount of bicarbonate or lime should be applied many times, or phosphate rock powder can be applied; for land reclamation and ecological reconstruction, filling some industrial and mining wastes, fly ash and so on can make the soil alkaline, generally sulfur, calcium chloride, gypsum, sulfuric acid, etc. Most mining soils lack organic matter and other nutrients. If reclaimed land is used for agricultural production, soil fertility must be restored first. Physical, chemical and biological remediation measures can be used to improve soil fertility.

\section{(3) Rehabilitation of soil environmental quality}

Physical repair: including mechanical engineering measures, high temperature pyrolysis, steam extraction, curing, vitrification, electro-osmotic method, etc. Mechanical engineering measures are physical transfer or isolation of contaminated soil to reduce pollution concentration or contact between pollutants and plant roots, such as guest soil, soil exchange, soil dump, surface soil removal and isolation. They are generally applicable to small and heavily polluted soils. High temperature pyrolysis and steam extraction are suitable for soils containing volatile and semi-volatile pollutants, which are decomposed or separated firstly, and then recycling; solidification and vitrification are the addition of solidifying agents such as cement, which make the soil granular or massive, and the pollutants are relatively stable, suitable for soils with low water content and no more than $6 \mathrm{~m}$ depth of pollutants; electro-osmotic method can clean the soil by electroosmotic flow or electrophoresis to bring contaminants in the soil to both ends of the electrode. It is not suitable for the soil with high permeability and poor conductivity, especially for the clayey soil which is difficult to be treated by other methods and has poor water adaptability.

Chemical remediation: includes chemical modifier method, chemical elution method, chemical grid method, etc. Chemical improvers are soils that are not heavily polluted. Chemical reactions between pollutants and improvers are used to reduce the water solubility, diffusivity and bioavailability of pollutants. Commonly used improvers include organic wastes (such as sewage sludge, garbage or clinker salts), and inorganic improvers (such as gypsum, zeolite, calcium chloride, phosphate, carbonate, etc.), which convert harmful chemicals into substances with low toxicity or poor mobility. Chemical leaching is a method of leaching soil with chemical solution. It is more suitable for light soil such as sandy soil, sandy loam soil and light loam soil, but it is easy to cause groundwater pollution, soil nutrient loss and soil denaturation. Chemical grating method is to place some solid materials (such as activated carbon, peat, macromolecule synthetic materials, etc.) which are both permeable and have strong ability to absorb or precipitate pollutants in the bottom or subsurface aquifers of contaminated deposits, so that organic pollutants can be retained in solid materials, so as to 
achieve the purpose of purification and remediation. It is only suitable for the remediation of shallow contaminated soil (3-12 m).

In summary, the main causes of mine pollution in the mining process are acid waste water, tailings pond, tailings slag and so on. Therefore, regional pollution control mainly focuses on these aspects. The treatment methods involve physical, chemical and biological fields. Firstly, the forms of heavy metals in soil are changed to stabilize and fix them. Secondly, various anti-seepage materials are used to prevent the migration and diffusion of heavy metals. It uses various technologies to remove heavy metals from soil in order to recover and reduce the content of heavy metals in soil. Phyto remediation technology is the most widely used method at present. Compared with other methods, it has the advantages of economy, environmental protection, simplicity and convenience, less disturbance to the environment, and there is no secondary pollution factor. Phytoremediation is a treatment technology that uses the absorption, volatilization, transformation and degradation of plants and their rhizosphere microbial systems to remove pollutants. The technology includes plant extraction, plant volatilization, rhizosphere filtration and plant fixation. Among them, plant extraction is the most important method in phytoremediation technology. Plant extraction is the removal of heavy metal contamination in soil by utilizing the super-enrichment ability of some specific plants to heavy metals. At present, it has been found that many kinds of plants can be used as hyper accumulative plants, and the selection of hyper accumulative plants must consider whether they are suitable for remediation of heavy metal contaminated areas. It is necessary to further strengthen the ecological pollution effects of heavy metals in the source-streamsediment and soil-plant systems in mining areas, and to establish a three-dimensional research system in time and space, taking into account various comprehensive factors. In addition, on the basis of synthesizing various environmental assessment systems, the practical application of remediation should be strengthened. At present, the most widely used technology is plant ecological remediation.

\section{Conclusions}

China is rich in mineral resources. Mining has become an important means of production activities and economic growth in China. There are nearly 300,000 mining areas in China. Due to the neglect of the protection of the surrounding environment in the mining process for a long time, especially with the rapid development of science and technology in recent years, the problem of mine ecological environment damage and pollution is very serious in China. The total area of land destroyed is nearly $4 \times 10^{6} \mathrm{hm}^{2}$ and it is still destroying at the rate of hundreds of thousands of hectares every year. The inducing factors of soil environmental problems in mining areas are complex, and the soil barrier factors are complex. The degradation of soil production function, environmental function and ecological function is prominent. Therefore, it is of great significance to study the soil environment and related issues in the mining area to scientifically and rationally restore the damaged ecological system in the mining area and ensure the safety of production, food security, ecological security and human settlements in the mining area. This paper studies the real-time detection method for heavy metal pollution in the soil of mining area, and applies it to the test analysis of a mining area. The results show that:

(1) The average contents of $\mathrm{Pb}, \mathrm{Cd}, \mathrm{Cu}$ and $\mathrm{Zn}$ are 671,24 , 82 and $117 \mathrm{mg} \cdot \mathrm{kg}^{-1}$, respectively, which are much higher than the background values of the corresponding soil heavy metal contents in this area, indicating that there is a significant accumulation phenomenon.

(2) The pollution index of $\mathrm{Cu}, \mathrm{Zn}$ and $\mathrm{Pb}$ in the soil of the mining area belongs to heavy pollution, and there are great differences among the three heavy metals in one-way pollution index. The pollution index of $\mathrm{Cu}, \mathrm{Zn}$ and $\mathrm{Pb}$ belongs to heavy pollution, and the pollution of $\mathrm{Cd}$ is relatively small. Among them, the pollution index of $\mathrm{Pb}$ is the largest among the four heavy metals, and the pollution is quite serious, especially at sampling sites 15 and 16 . The pollution index is as high as 15.92 and 49.34, respectively.

(3) The main pollution sources of $\mathrm{Pb}, \mathrm{Zn}$ and $\mathrm{Cu}$ are the mining and smelting activities of lead-zinc sulphide ores in the mining area and the secondary pollution caused by slag after mining. The first principal component of $\mathrm{Cd}$ pollution sources is mainly mining activities of non-ferrous metal mines, and the second principal component is mainly "three wastes" discharge from mining areas.

\section{Acknowledgement}

This research is supported by Key Research Projects of Henan Provincial Universities (No. 16A170001).

\section{References}

Ali R., Hossein H., Seyedeh B.F.M., Sara H. and Nima J. (2019), Assessment of heavy metals contamination in surface soils in meiduk copper mine area, Se Iran, Earth Sciences Malaysia, 3, 1-8, DOI: 10.26480/esmy.02.2019.01.08

Amjad H., Hamid S., Niaz Y., Ashraf M., Yasir U., Amna C., Ali A. and Daud M.W. (2019), Efficiency assessment of wastewater treatment plant: a case study of Pattoki, District Kasur, Pakistan, Earth Sciences Pakistan, 3, 1-4

Chen H., Zhang X. and Zhou X.M. (2017a), Electrochemical properties and modification of novel material $\mathrm{Na}_{4} \mathrm{MnV}\left(\mathrm{PO}_{4}\right)_{3}$, Journal of Jilin University (Science Edition), 55, 253-258.

Chen Y., Liu Y. and Chen X.R. (2017b), Simulation and evaluation method for pesticide residue pollution based on visual analysis techniques, Computer Simulation, 34, 347-351.

Cheng Y.W., Ng K.H., Lam S.S., Lim J.W., Wongsakulphasatch S., Witoon T., and Cheng C.K. (2019), Syngas from catalytic steam reforming of palm oil mill effluent: An optimization study, International Journal of Hydrogen Energy, 44, 9220-9236.

Chicalote-Castillo D., Ramirez-Garcia P. and Macias-Rubalcava M.L. (2017), Allelopathic effects among selected species of phytoplankton and macrophytes, Journal of Environmental Biology, 38, 1221-1227.

Hamad R., Balzter H. and Kolo K. (2019), Assessment of heavy metal release into the soil after mine clearing in Halgurd- 
Sakran National Park, Kurdistan, Iraq, Environmental Science and Pollution Research, 26, 1517-1536.

Huang J., Nie R. and Cao W.Q. (2017), Design of LED driver power without electrolytic capacitor, Chinese Journal of Power Sources, 41, 138-141.

Islam M.M., Ahmed A.Z., Kabir S.F., Islam R. and Molla M.A.I. (2020), Optimization of photodegradation conditions of rhodamine $B$ in water with dye-sensitized titanium dioxide, Journal Clean Was, 4, 28-31.

Karbassi A. and Marefat A. (2017), The impact of increased oxygen conditions on heavy metal flocculation in the Sefidrud estuary, Marine Pollution Bulletin, 121, 168-175.

Khoo S.C., Phang X.Y., Ng C.M., Lim K.L., Lam S.S. and Ma N.L. (2019), Recent technologies for treatment and recycling of used disposable baby diapers, Process Safety and Environmental Protection, 123, 116-129.

Laili I.N. and Amid A. (2019), A review on the identification and analysis of heavy metals in herbs using inductively coupled plasma mass spectrometry (ICPMS), Environmental Contaminants Reviews, 2, 1-5.

Leung H.M., Duzgoren-Aydin N.S. and Au C.K. (2017), Monitoring and assessment of heavy metal contamination in a constructed wetland in Shaoguan (Guangdong Province, China): bioaccumulation of $\mathrm{Pb}, \mathrm{Zn}, \mathrm{Cu}$ and $\mathrm{Cd}$ in aquatic and terrestrial components, Environmental Science and Pollution Research, 24, 9079-9088.

Li H.G. and Shi J.S. (2017), Monte Carlo simulation model for calculating cascade utilization capacity of power batteries, Automation \& Instrumentation, 72-74.

Li X., Meng D. and Li J. (2017), Response of soil microbial communities and microbial interactions to $\hat{A}$ long-term heavy metal contamination, Environmental Pollution, 231, 908-917.

Liew R.K., Chai C., Yek P.N.Y., Phang X.Y., Chong M.Y., Nam W.L., Su M.H., Lam W.H., Ma N.L. and Lam S.S. (2019), Innovative production of highly porous carbon for industrial effluent remediation via microwave vacuum pyrolysis plus sodiumpotassium hydroxide mixture activation, Journal of Cleaner Production, 208, 1436-1445.

Liu Q.F. (2017), Initial rotor position estimation method for interior permanent magnet synchronous motor, Journal of Power Supply, 15, 132-137.

Munoz-Colmenares M.E., Sarma S.S.S. and Nandini S. (2017), Seasonal variations of rotifers from the high altitude Llano reservoir (State of Mexico, Mexico), Journal of Environmental Biology, 38, 1171-1181.

Nethaji S., Kalaivanan R. and Viswam A. (2017), Ical assessment of heavy metals pollution in surface sediments of Vellar and Coleroon estuaries, southeast coast of India, Marine Pollution Bulletin, 115, 469

Ng K.H., Cheng Y.W., Lee Z.S., Khan M.R., Lam S.S. and Cheng C.K. (2018), Experimental evaluation and empirical modelling of palm oil mill effluent steam reforming, International Journal of Hydrogen Energy, 43, 15784-15793.

Osazuwa O.U., Khan M.R., Lam S.S., Assabumrungrat S. and Cheng C.K. (2018), An assessment of the longevity of samarium cobalt trioxide perovskite catalyst during the conversion of greenhouse gases into syngas, Journal of Cleaner Production, 185, 576-587.

Paneru N., Adhikari P. and Tandan P. (2020), Management of purple blotch complex of onion (Allium Cepa Cv Red Creole)
Under field condition in rukum-West, Nepal, Malaysian Journal of Sustainable Agriculture, 4, 71-74.

Pang Y., Gao H. and Wu S. (2017), Facile synthesis the nitrogen and sulfur co-doped carbon dots for selective fluorescence detection of heavy metal ions, Materials Letters, 193, 236239.

Prabal B., Rahman S.H., Barua S. and Ismail M.M.R. (2020), Climate change vulnerability and responses of fisherfolk communities in the South-Eastern coast of Bangladesh, Water Conservation and Management, 4, 20-31.

Qolipour M., Mostafaeipour A., Saidi-Mehrabad M. and Arabnia H.R. (2019), Prediction of wind speed using a new Greyextreme learning machine hybrid algorithm: A case study, Energy \& Environment, 30, 44-62.

Rahman M.R., Rahman M.M. and Chowdhury M.A. (2020), Assessment of natural regeneration status: the case of Durgapur hill forest, Netrokona, Bangladesh, Geology, Ecology, and Landscapes, 4, 121-130.

Ramdani S., Amar A. and Belhsaien K. (2018), Assessment of heavy metal pollution and ecological risk of roadside soils in tlemcen (algeria) using flame-atomic absorption spectrometry, Analytical Letters, 51, 1-20.

Rosen V. and Chen Y. (2018), Effects of compost application on soil vulnerability to heavy metal pollution, Environmental Science and Pollution Research, 25, 35221-35231.

Shahsavari A., Yazdi F.T. and Moosavi Z. (2019), A study on the concentration of heavy metals and histopathological changes in Persian jirds (Mammals; Rodentia), affected by mining activities in an iron ore mine in Iran, Environmental Science and Pollution Research, 26, 12590-12604.

Shalmashi A. and Khodadadi F. (2019), Ultrasound-assisted synthesis of biodiesel from peanut oil by using response surface methodology, Energy \& Environment, 30, 272-291.

Stihi C., Popescu I.V. and Frontasyeva M. (2017b), Characterization of heavy metal air pollution in romania using moss biomonitoring, neutron activation analysis, and atomic absorption spectrometry, Analytical Letters, 50, 2851-2858.

Szentgyörgyi H., Moroń D. and Nawrocka A. (2017), Forewing structure of the solitary bee Osmia bicornis developing on heavy metal pollution gradient, Ecotoxicology, 26, 10311040.

Yang C.K., Pan Y. and Guo J.G. (2017), Content delivery in wireless mesh network based military information system, Journal of China Academy of Electronics and Information Technology, 12, 642-648.

Zephania N.F, Suiven John P.T. and Martin F. (2019), Eucalyptus tree colonization of the Bafut-Ngemba forest reserve, North West region, Cameroon, Environment \& Ecosystem Science, 3, $12-16$. 